\title{
15 Developing and using indicators of emerging and enabling technologies ${ }^{1}$ Leonid Gokhberg, Konstantin Fursov, Ian Miles and Giulio Perani
}

\section{INTRODUCTION}

Statistical frameworks have usually been regarded, with some justification, as like Minerva's owl, alerting us to important knowledge only at the end of the day. Statisticians have been understandably reluctant to introduce modifications to their systems whenever a major breakthrough in technology or economic organization is announced. But this has meant that it can take a very long time for indicators to catch up with important developments. Often observers - and decision makers - are left only with impressionistic claims or consultancy reports. This becomes particularly problematic when one is dealing with emerging technologies, especially those that have the potential to transform wide swathes of social and economic activity. Is it possible to construct statistical frameworks that will allow us to monitor and track developments in such technologies from an early stage?

Extensive experience has been gathered from the development of the ICT revolution over the last half-century. This has been very informative when it has come to establishing statistics and indicators capable of addressing biotechnology, another set of developments with far-reaching implications. Now, while the ICT revolution is still ongoing, and the biotechnology revolution is just beginning to demonstrate its scope, we are confronted with another field (or set of fields) of potentially pervasive significance - the emerging technologies collectively known as nanotechnology. The fact that many commentators talk of 'converging technologies' underlines the scale of the task.

However, it is vital to capture more of the critical developments at early stages, even if only imperfectly, for a number of reasons. One reason is that we will then be better equipped to identify and examine different rates of development that present themselves in different regions and sectors. This chapter considers the scope for capturing developments in technology at an early stage, rather than waiting for the applications of this technology to be so widespread that they can no longer be ignored. It is also an 
attempt to provide ideas for developing a general framework to measure the extent to which a technology has become an enabling technology, that is, an engine for production of goods and services across various economy sectors.

Such a framework can be built on the lessons learned from statistical work around ICT and biotechnology; indeed, this has already resulted in practical efforts to establish new frameworks. The chapter will review national experiences, and draw out the implications for further efforts around nanotechnology and emerging and enabling technologies (EETs) in general.

The Russian experience is particularly interesting, because this is a case where data production has been deemed necessary to inform decision making. It also demonstrates the scope for using technology foresight to orient statistical work, and suggests that a combination of improved statistical monitoring of ongoing developments, and foresight analysis of anticipated technology and technology applications, represents a powerful approach to achieving early footholds by way of indicators of emerging technologies in concrete circumstances. Foresight exercises are especially helpful when new, forward-looking classifications for technology areas and allied goods and services are to be provided in the absence of any standardized schemes and statistical evidence. The result in this case has been elaboration of established statistical systems, so that nanotechnology developments can be assessed, while not reorganizing the harmonized frameworks so extensively as to reduce the scope for conventional historical or cross-national comparisons (whether or not these included attention to nanotechnology-related issues). The chapter will outline the main requirements for such an approach to be effectively implemented and its results utilized; it concludes with proposals for future methodological and conceptual development.

\section{EMERGING, ENABLING AND GENERAL- PURPOSE TECHNOLOGIES}

There is widespread and increasing interest in the development of indicators for measuring EETs. Such indicators can be used for monitoring their arrival, development and subsequent diffusion, as well as their key social and economic impacts - all of these are topics that concern national and regional policy makers, and are often of interest to industrial actors, research institutions, education bodies and so on. The growing integration of new technologies into economic and social processes over the last 50 years has been accompanied by a growing understanding that the 
resources allocated for augmentation of knowledge, for evaluation of effects and consequences of experimental activities, and for support to innovation and diffusion need sophisticated analysis. One result has been efforts to establish relevant statistics, allowing for standardized and internationally harmonized measurement of science and technology (S\&T) in terms of inputs (R\&D and other expenditures and labour forces), outputs (scientific publications, patents, technology exports etc.), outcomes (diffusion of innovations) and to a limited extent impacts (productivity trends, for example). These can contribute to evidence-based S\&T policy making at national and regional level.

Emerging technologies have been accepted as one of the pillars of future innovation-based economic growth. A number of surveys focusing on specific 'technological domains' have already been carried out in several countries, to identify and characterize certain S\&T areas, to estimate their economic and social effects, as well as to explore public attitudes and perceptions (especially since some technologies, such as nuclear energy and genetic modification of organisms, have proved highly controversial). These studies were not just about well-established domains such as ICT and biotechnology, for which statistical measurement is conducted on a regular basis in many developed countries, but also on less harmonized areas, such as nanotechnology, 'green' technology or other types of 'advanced' or 'emerging' technologies.

The notion of 'emerging technologies' is widely employed, and is used here to focus our attention on developments that: (a) result from contemporary advances in a given field of knowledge; (b) are rapidly evolving; and (c) have high potential to result in inventions and innovations with significant societal and economic impacts. A set of technologies, or a growing technology area, is involved, with novel ways of applying scientific or technical knowledge for practical purposes to transform energy, matter or information. A well-known case is microelectronic technologies, which allowed for much more powerful and small-scale devices as compared to those based on thermionic valves. The new transformations, or ways of transforming things, that they offer are such as to be of considerable potential influence on the applicability of other, even well-established technologies. (For example, development of magnetic resonance imaging in medicine can reduce application of existing systems using X-rays.) Finally, these potentials are liable to produce - direct and indirect - economic and societal impacts of the emerging technologies on final users over the long term.

It is almost impossible to distinguish between different technologies when they are at the early stage of their life cycle (at least, with the use of traditional statistical surveys), as they appear to be uncategorized and 
chaotic where merely expectations and visions guide the field, rather than facts and prime examples 'out there' (Van Merkerk and Smits 2008). One of the problems here is that several competing technological solutions to common problems can always be found but one or other wins out. As they are therefore different from the later stages of technology development owing to the absence of transparent and structured relations between actors, there could also be 'false starts' when the eventual technology regime is quite different from the first attempts to institute it. The Web and Videotex competition in the mid-1990s is an exemplar case in this regard (Carey and Elton 2009). Another problem is methodological. The new developments tend to be assimilated into existing statistical categories until their significance is more definitively established. Thus the general definition of emerging technologies above has to be set against existing and standardized definitions of the most common technological domains in which particular examples or cases, representing nationally relevant rising technology areas or particular priorities in technology development, should be taken into consideration, at least for a certain reference period. In particular, emerging technologies should be distinguished from socalled 'enabling technologies', considered as already-available inventions or innovations that are likely to be applied in a foreseeable period of time and to drive radical change in the capabilities of a user in its use of other technologies. Allied irreversibilities that emerge in the ongoing activities of researchers, policy makers and organizations engaged in knowledge production create a need for agenda-building processes (Van Merkerk and van Lente 2005), when spontaneous and open socio-cognitive patterns are to be limited by user needs and expectations, policy issues and national interests. Examples are EU key enabling technologies, ${ }^{2}$ and official lists of S\&T priority areas in Russia and the USA. It should be noted that some enabling technologies may not be emerging, in the sense that they involve upgrading and more fully exploiting a known technology, but for many of them it is a bit of a struggle to make them commercializable.

Finally, when new enabling technologies have the potential to become widely used across the entire economy or a core technology has a substantial and pervasive effect across the whole of society, it is often termed a 'general-purpose technology' (GPT). This stage is characterized by more sustainable relations between various actor-networks involved to share beliefs that the GPT is spawning innovations in multiple technological areas. Previous research has suggested that a GPT must have at least three attributes: pervasiveness, an innovation spawning effect, and scope for improvement (Helpman and Trajtenberg 1994). Some authors add a fourth element to the definition of a GPT, that of wide dissemination (Lipsey et al. 1998), although this element is often considered a logical 
consequence of the other three attributes. Taking these criteria as a reference point, researchers (e.g. Youtie et al. 2008) show that new and growing areas such as bio- and nanotechnologies have a chance to be followed by a sequence of events in which a major technological innovation is preceded by a number of smaller incremental inventions that expand the range of applicability of the core technology, bringing them to the group of GPTs such as electricity, ICT and others that have been previously documented as major breakthroughs.

At least three classes of emerging technologies can be identified:

1. 'Revolutionary' technologies, based on major advances in knowledge in some field of science (and applied science), with potential for wide applicability because they propose new approaches to providing solutions to problems widely encountered in social and economic processes - Freeman and Perez's heartland technologies, such as electrification, microelectronics and genomics (Freeman and Perez 1988). Often several related breakthroughs work synergistically - software, optronics, microelectronics, for example.

2. 'Convergent' technologies, where dramatic advances in technological knowledge across several such fields are applied in combination - as in the NBIC technologies (nano, bio, ICT and cognitive technologies), where development in each of the sub-areas is heavily reliant on development in the others, but where the underlying fields of knowledge are from domains with little prior relationship. ${ }^{3}$

3. Problem-oriented technologies, such as 'green' technologies or 'advanced manufacturing methods', that are identified more on the basis of the set of problems that they address than of the core knowledge on which they are built (as in the first two groups). Often there may be a critical breakthrough around which many other solutions cluster - such would be the case if one achieved readily commercializable breakthroughs in, say, renewable energy production or energy efficiency across a wide spectrum of products. Until this is clearly the case, however, the emerging technology label is applicable on account of the devotion of substantial concerted efforts to achieving what is hoped will be far-reaching impacts from development of a multiplicity of partial solutions to the set of problems that has been identified here.

Current classifications of emerging technologies focus most attention on a few technological areas - and these may be defined in several, sometimes contradictory, ways. Biotechnology is a good case in point, being still in its specific segments considered an 'emerging' technology but also influenced by a process of 'convergence' - and as having the potential of 'enabling' 


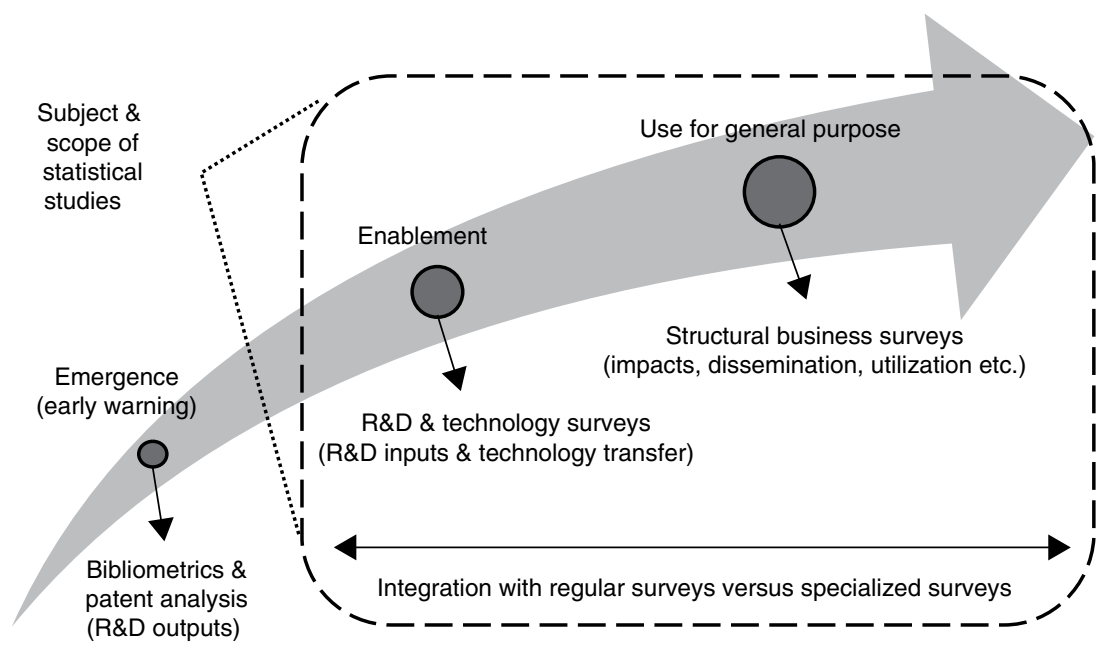

Figure 15.1 Measuring emerging, enabling and general-purpose technologies: scope of statistics

other technologies to be applied in several fields having 'general-purpose' implications. Basically, by 'biotechnology' a quite large technological area is meant, where specific 'sub-domains' (including some overlapping with the 'nanotechnology' domain) can have different features.

In order to develop the framework in a structured and coherent way, it is important to denote the subject and the scope for statistical studies (Figure 15.1). On the one hand it is important to distinguish the moment when (a) a specific technology starts to 'emerge' and (b) when it becomes relevant for measurement in statistical terms such as 'scientific productivity' and technology creation, diffusion and use, and production of technology-enabled goods and services.

The identification of the moment of technology emergence is strongly connected to the provision of a common definition and general classification principles that can help to describe the nature of the area uncovering one or more of its 'sub-components' and reflecting distinctive features. Various analytical exercises based on the analysis of bibliometric and patent data can be quite helpful in solving the task. Some examples of analysis and reporting of emerging technology indicators that can help to monitor 'hot research areas' and reveal how multidisciplinary, translational networks are evolving can be found in OECD (2010: 28-9). As for the strategies of bibliometric analysis, at least three basic methodological approaches can be identified. The first one is to visualize the structure of knowledge and key emerging trends. It is based on keyword analysis 
(mainly on first appearance and life cycle of the keywords used to describe scientific articles) and helps to identify growing research areas and emerging topics as well as the disciplinary structure of the whole of knowledge (Chen 2006; Cobo et al. 2011; Morel et al. 2009; Van Raan 1996). The second approach is focused on analysis of research areas already accepted by the scientific community as likely to contribute to future development. It is based on citation indexing of publications produced in a particular research area and allows identifying certain research clusters (Shibata et al. 2008). A similar approach is applied in patent analysis (Daim et al. 2006). Finally, the third approach evidently combines both the previous strategies and detects fast-growing research areas in the entire field of knowledge and depicts the life cycles of research fronts (Guo et al. 2011, Upham and Small 2010). One more strategy is based on linking of patents to scientific literature through co-citation analysis (OECD 2010: 36). It provides an indication of the type of scientific knowledge certain types of innovation, for example 'green innovation', draw on. These mapping tools become a kind of early warning system that helps to identify areas of high $\mathrm{R} \& \mathrm{D}$ potential and can also be used productively as a shared source of data providing basis for more detailed analysis and expert sounding.

The question of statistical measurement focuses on the relation of a technology field with existing institutionalized units, such as fields of science (scientific disciplines), sectors of R\&D performance and so on, as well as existing S\&T policy frameworks (e.g. priority settings and funding instruments). It brings statistics to the field, identifies the scope for measurement and highlights the need for elaboration of classification approaches and an indicator system for measuring inputs, outputs and impacts of EETs within the existing structure of national statistical surveys. It is common to find that such technologies cross several established disciplines and fields of knowledge. The complex interdisciplinary character of such areas is one reason why methodologies to detect and describe them are particularly challenging, with measurement approaches still in the testing phase. One typically has very limited knowledge about the main sources of growth and potential application of EETs. Policy makers require verifiable and comparable data, based on consistent methodology and harmonized approaches, and presented in a timely and useful fashion. Statisticians, meanwhile, lack standard definitions and classifications for the growing areas, and have to deal with relatively rare populations, and incomplete knowledge of outputs and impacts. It should be admitted that no single methodology can meet the abovementioned challenges; rather a multifactorial suite of databases, surveys, forecasting and foresight approaches, and case studies provides a mosaic representation of activities, players, linkages and issues within the field. The importance of such 
a measurement mix for statistical description of EETs requires rethinking available approaches to the development of an operational definition and classification of technologies for statistical purposes; looking at the best national practices in knowledge measurement will be important for learning and for inspiration.

\section{APPROACHES TO THE DEVELOPMENT OF AN OPERATIONAL DEFINITION OF TECHNOLOGIES FOR STATISTICAL PURPOSES}

The development of approaches to describe S\&T and innovation processes as proper categories goes back to the 1920s when national policy-making organizations in the USA, Canada and later Great Britain started campaigns to measure costs of national research laboratories and compute 'national research budgets'. The word 'research' became central to these studies. Although it had been measured, the question 'what is research?' was originally left to the questionnaire respondent to decide (Godin 2005). It took several decades before research activities came to be defined precisely for statistical purposes and first adopted in a form of internationally accepted methodological guidelines by OECD member countries in Frascati (Italy) in 1963. Since then the OECD Frascati Manual (OECD 2002) became a major methodological source focusing on definitions, classifications and methodologies for measuring the expenditures and human resources devoted to $R \& D$.

The discussion on the construction of an operational definition of technology begins with the introduction of the OECD Oslo Manual in 1992 that was initially aimed at providing approaches to measuring the use and planned use of technologies (Gault 2010: 39-43). Despite the fact that technological innovation was taken as a central notion and an object for statistical observation the manual included no discussion on the concept of 'technology'. Technology in the wide sense was intended to capture both hardware and software aspects, as well as including productive knowledge, or production capabilities, more generally. The OECD was following a Schumpeterian view that radical innovations were motivated by a concern for dynamics at the level of industrial organization, so these guidelines were dealing only with new 'products and processess, which are technological innovations proper' (OECD 1992: 28). The second edition of the Oslo Manual (OECD/Eurostat 1997) inherited the semantic uncertainty of the term, especially when used in multilingual contexts, and in terms of outlining an analytical framework for the manual. The technological aspect played a major part in the then Oslo Manual's defini- 
tion of innovation: it only concerned technological product and process innovations - those that must be 'technologically' new or improved. However, there is a certain amount of ambiguity: "the term "technological" is not defined as such: it therefore has shades of meaning which can vary from one country to another, and even from respondent to respondent within the country' (Gimel 2003: 4). Technological development was concerned with processes leading to value-added outputs and measurable changes in it, such as increased productivity or sales (OECD/Eurostat 1997: 47, 52-5). In both cases it dealt with the respondent's understanding of the measurement issues similarly to an early stage of R\&D data collection, as mentioned above. In the third edition of the Oslo Manual the word 'technological' was removed from the definitions 'as the word raises a concern that many services sector firms would interpret "technological" to mean "using high-technology plant and equipment" and thus not applicable to many of their product and process innovations' (OECD/Eurostat 2005: 17). Technological product and process innovations are no longer the subject of the manual. Focus is now placed on the close concepts of 'new or significantly improved product or process' and include only 'implemented' products and processes that are 'introduced on the market' or 'brought into actual use in the firm's operations' (ibid.: 47).

Only two of the OECD manuals actually consider how the concept of 'technology' can be defined for statistical purposes: one for compiling technology balance of payments (TBP) (OECD 1990), and the Handbook on Economic Globalisation Indicators (OECD 2005a). The Patent Statistics Manual (OECD 2009a) shows how technologies can be classified. These manuals interpret the concept of 'technology' in its basic meaning of 'technical knowledge'. More specifically, while the Patent Statistics Manual recommends use of the standard international patent classification to identify relevant technological areas, the TBP Manual points out that the concept of 'technology' should be qualified in terms of 'utilisation' (i.e. 'potential use' and economic value, as for patents in general), 'scope of application' (generality versus specificity), and 'novelty and exclusivity'. Thinking about 'technology' as a combination of definite pieces of technical knowledge, or 'techniques', may be useful in creating statistical frameworks for emerging technologies. In the Handbook on Economic Globalisation Indicators the technology definition is based on Mansfield's study (1983) and defined as a 'stock of (physical or managerial) knowledge which makes it possible to make new products or new processes', which includes 'implying the constant addition of new knowledge to existing knowledge that may make the existing knowledge totally or partially obsolete' (OECD 2005a: 166). As this knowledge is quite heterogeneous, the Handbook proposes measuring it in embodied forms of tangible and 
intangible goods (equipment, software etc.) and incorporated in patents, licences, know-how or technical assistance, external databases (Internet), published research findings, knowledge acquired through takeovers or mergers, or through cooperation with other firms or sectors (ibid.). A supplementary distinction lies in identifying high-tech sectors and products. The former is based on an R\&D intensity criterion; the latter supplements a sectoral classification by including additional criteria either answering countries' national specifics or using the UN Standard International Trade Classification for cross-country comparisons at the international level.

Even a quick overview of different fields of study shows that the concept of 'technology' is unclear, potentially used with several different meanings and potentially misleading. ${ }^{4}$ The main problem lies in the widespread use of the concept that (in addition to the basic definition of being the 'practical application of knowledge's) includes references to specific techniques (i.e. the 'self-assembly' nanotech technique for microprocessors), single devices (i.e. transistor technology), as well as to 'assemblage of different techniques' (i.e. 'laser' technology), technological domains (i.e. 'biotechnologies'), or complex technological systems (i.e. the 'aircraft gas turbine') ${ }^{6}$ and also to potential applications of 'technologies' (i.e. 'green technologies').

The concept of 'technology' is also affected by a serious risk of misunderstanding when used in different cultural and linguistic contexts. It can be clarified by comparing its meaning with that of a complementary word such as 'technics'. According to the OECD TBP Manual, this problem exists in the French language ${ }^{7}$ but it seems even more relevant for the German and Russian languages. ${ }^{8}$ An analysis of these potential inconsistencies in the understanding of the concept of technology may prevent further difficulties in developing a generally agreed system of technology classification.

The current use of the 'technology' concept is spreading as a result of its large success in the US culture. Following its early adoption in the mid-nineteenth century (when, for instance, the Massachusetts Institute of Technology was established by following the German tradition of the 'Polytechnic' schools), the concept of technology evolved in parallel with the Second Industrial Revolution, usually referred to as the 'Technological Revolution' (Landes 2003; Smil 2005). On the basis of the increasing awareness of the potential of new technical applications of science to change the economic and social structure of the Western countries, as well as strongly influencing the everyday lives of their citizens, the concept of technology gathered momentum and began to be used to identify the 'pervasiveness' and 'dominance' of machines on various aspects of our lives, at least in comparison with the previous age. 
Deriving from the concept of 'Technik', largely used by German sociologists and economists, the 'American' concept of technology has been, since the end of the nineteenth century, strongly associated with the economic and social effects of the practical application of scientific findings in industrial and applicative processes (Schatzberg 2006). It soon became apparent that the diffusion of 'new technologies' was shaping a new social structure by influencing habits, cultures, economic relationships and social infrastructures (Marx 2010).

Two main lessons can be drawn from the analysis of the problems of definition related to the evolution of the concept of 'technology' in the USA and in most of the Western countries. First, this concept has become practically all-encompassing in its common usage, and its inclusion in a statistical framework must be given a clear definition, stressing the need for a full exploitation for statistical purposes of related terms and concepts (e.g. knowledge, technique(s), process, domain(s) etc.). Second, it should be stressed that a technology is more a social phenomenon than a scientific or technical one. It should also be mentioned that a technology development in itself can be identified in terms of 'social relationships' and with reference to its ability to establish them (e.g. see Gault 2011: 4-5). In this perspective, a technology exists since it can have a clear social and/or economic impact. A logical consequence is that the term 'emerging technologies' is rather controversial in the sense that if a 'technology' can be identified, it means that such technology has already 'emerged' and some evidence of it can be found in specific social processes.

For present purposes the general definition of technology contained in the OECD Measuring Productivity manual (OECD 2001) and subsequently in the OECD Glossary of Statistical Terms (OECD 2008) can be applied. Both appeal to the general definition, formerly introduced by Griliches (1987), and suggest that 'technology refers to the state of knowledge concerning ways of converting resources into outputs' (OECD 2008: 536) and appears 'rather in its disembodied form (such as a new blueprint, scientific results, new organizational techniques) or embodied in new products (advances in the design, quality of new vintages of capital goods and intensive inputs)' that link them to innovation and productivity measures (OECD 2001: 8).

To be consistent with these findings, a revision of the current system of technological classifications (or, to some extent, 'para-classification') should be proposed. The point here is whether definitions such as 'enabling technologies' or 'general-purpose technologies' or 'advanced technologies' can be effectively used in a statistical framework, or if some innovative approach is needed in order to avoid a potential confusion among these quite similar - and partially unclear - definitions. 
For the purposes of this chapter, technology is considered as ways of knowledge application in which humans can effect transformations of the world (of things, of materials, of energy, of symbols, of organisms). Moreover, emerging technologies are then taken to mean application of new knowledge, or knowledge that is itself 'emerging' (i.e. underdeveloped) to create new or improved ways of transforming the world, where these transformations are ones that are, or are likely to be, those of widespread social and/or economic significance. Then there are the heartland (core) technologies - those components or devices that fundamentally accomplish these transformations: power stations, grids, electric motors, microprocessors, computers and several other important techniques such as nanotechnology tools. When the transformations are ones that are (or can be) very widely employed, and when the new technologies offer radical improvements in the price, performance or other desirable characteristics of these transformations, one can take a look at new heartland technologies that may trigger technological revolutions. There can be components (e.g. microprocessors), platforms and symptoms (computers, the Internet, social media etc.), and techniques (e.g. text processing) that are widely used.

In any case, identification of emerging technologies (or 'techniques') requires using specific methodologies, drawing on the definition proposed earlier, and taking into account the particular problems associated with converging and problem-oriented technologies. For example, the NBIC technologies mentioned above pose problems due to the convergence of activities and knowledge from widely dispersed domains; specific methodological guidelines will be required for their measurement and it may be that only general recommendations on how to deal with them can be included in the overall statistical framework at present. The problemoriented contenders for the title of emerging technologies may, in the absence of new heartland technologies, have to be measured almost exclusively in terms of social and economic impacts given that they are linked more in terms of these impacts than in terms of their industrial or technological origins.

\section{TOWARDS THE 3D CLASSIFICATION OF TECHNOLOGIES}

The main statistical frameworks are not designed to support analysis of the knowledge economy and society as well as current technological development. Although the introduction of groupings for bio- and nanotechnology $\mathrm{R} \& \mathrm{D}^{9}$ into current versions of NACE and of the North American 
Industry Classification System (NAICS) is an important breakthrough in this regard, there is still lack of internationally standardized and commonly used classifications and data collection by technology area with respect to technology-specific information, of relevance for analysis in the fields of bio- and nanotechnology as well as in new materials and ICT (Veugelers 2007: 43). In current statistical practice industries are classified in terms of sectors (ISIC, NACE) for which data on employment and expenditures are collected; jobs are classified in terms of occupations (ISCO) and educational qualifications in terms of programmes (ISCED); product classifications (CPA) cover goods and services - but the groups here are largely derived from the sectors used in NACE. Typically the references to technology are relatively indirect ones - a set of firms that manufactures computers or a set of jobs that produces software, for example, can be identified, but the particular underpinning technologies are usually only sketchily outlined, with newer methods and tools rarely being visible (see Box 15.1). It creates an even greater problem when measuring biotechnology that lacks a core 'sector' that can be immediately identified for the purpose of collecting data (Box 15.2). Research fields are classified in various ways (e.g. the Frascati Manual (OECD 2002) 'Fields of Science and Technology' (FOS)), and scientific journals can be considered according to fields of study. Perhaps most relevant to the discussion, patents are grouped according to a technology area in line with the International Patent Classification (IPC). This classification system can refer to quite detailed technology developments, but patent data are rarely integrated into economic accounts. In principle, such data can be used to explore which sectors or regions are generating technological knowledge in particular fields.

For certain technology areas (e.g. bio- and nanotechnologies) some countries use national ad hoc classifications (e.g. technology areas, types of goods and services etc.), so as to generate information on industrial activity, skill shortages and related topics surrounding new technologies.

The most relevant problems reported by countries are related to:

(a) methodological issues, in particular to technology (or emerging technology) detection and classification;

(b) the selection of a proper level of aggregation (a single technology, a (intermediate) technology domain, or a larger technology area);

(c) identification of statistical units and sampling, understanding by respondents and achieving a relevant response rate.

In addition, it is widely reported that there are problems in gaining attention and support from policy makers, national business or professional associations when it comes to the statistical measurement of technologies. 


\section{BOX 15.1 MEASUREMENT APPROACHES IN ICT STATISTICS}

The ICT revolution was analysed in so-called 'neo-Schumpeterian' terms (e.g. Freeman and Perez 1988), as techno-economic paradigm change involving a revolutionary heartland technology. The new ICTs are seen as representing more than just a further step in the steady evolution of information activities (Machlup 1962; Porat 1977), and in the slow process of application of technologies of all types to information processing (Beniger 1986). A vast range of changes in the use of information is under way as a result of the cheapening of programmable information-processing power, through the use of microelectronics. Since the ICT revolution has largely been based upon the cheapening and increased performance of the core technology of microelectronics, it might seem reasonable to focus on devices that use this heartland technology - but what then about the software required to realize the utility of ICT, the services that are created? And if anything using microelectronics is classified as an ICT device (rather than, say, an ICT-enabled device), this would mean that as more and more products come to incorporate silicon chips (not only computers, phones, audiovisual products and robots, but also cars, household appliances, devices used in stores and hospitals, even 'smart buildings' and 'smart grids'), all of these might be classified as if they were equally ICTs.

One solution introduced in Miles (1991) is to discriminate between:

(1) Heartland ICT components (silicon chips, etc. - scope should be left for future developments in defining these: for instance, optronics might well at some point displace microelectronics from its leading role in ICT. The functions that are affected are more important than the specific materials that achieve this).

(2) The core ICT products, such as computers and telecommunications equipment and services, which provide generalpurpose information-processing functionality as their main output.

(3) ICT-using products, which may incorporate dedicated chips and embedded computers, or be controlled through telecommunications or other means, but whose main 
functionalities will often involve effecting physical, chemical or biological changes (e.g. moving things, maintaining them, changing people's physical health status etc.). Note that this definition would assign robotics and similar automated processes and equipment to this category.

(4) Non-ICT-using products, which may or may not be embedded within systems which include other elements that are ICT-using, and may or may not have been produced with ICT assistance (e.g. a tin of food in a supermarket may have been produced through the use of robotics, and may carry a bar code which enables automated check-out in a supermarket that uses ICT - but it is not itself ICT).

The 'ICT revolution' features the development of potentials in category (1), and the application and diffusion of these potentials in categories (2) and (3) (where there may be many 'swarms' of innovation). Greater shares of category (4) would be expected to be produced and delivered through ICT-using systems. Furthermore, the economy as a whole becomes more ICT-intensive, which is not to say that everything is ICT. The sort of distinction between ICT products and ICT-enabled products outlined above became embedded in the statistical classifications used by the OECD, in particular, although the various studies this organization commissioned on the information economy more broadly also take into account the specific information and communication products and services enabled through new ICTs digital content, e-commerce, social media and the like.

According to the Guide to Measuring the Information Society (OECD 2011), activity in manufacturing products of a candidate activity is identified as ICT in cases where they are intended to process and communicate information, as well as to transmit and display it, or to use electronic processes to detect, measure and/or record physical phenomena, or to control a physical process. In service activities, the products of a candidate activity must be intended to enable the processing and communication of information by electronic means. This definition has allowed statisticians to use existing structural business statistics, such as employment, turnover, wages and salaries, and added value to access the size and the structure of the ICT sector (Gokhberg and Bøegh-Nielsen 2007). 


\section{BOX 15.2 MEASUREMENT APPROACH IN BIOTECHNOLOGY STATISTICS}

Biotechnology development refers to the social and economic impacts of developing technologies that allow life to be manipulated at the level of genes. It consists of a group of related technologies with applications in many different economic sectors - agriculture, forestry, aquaculture, mining, petroleum refining, environmental remediation, human and animal health, food processing, chemicals, security systems - and in many industrial processes. It is the range of current and potential applications, together with their economic, environmental and social impacts, that creates policy interest in obtaining high-quality indicators for biotechnology.

The first attempts to measure biotechnology focused on R\&D activities in the late 1980s. Early measurement showed rapid increases in R\&D spending, almost doubling every second year (Rose 1997). This was a sign that businesses were adopting biotechnology. Then, in the late 1990s, statistical offices of some OECD member countries (Canada, New Zealand and France) initiated their first dedicated surveys of biotechnology activities in the industrial sector. The main focus of these surveys was firms that were actively engaged in the use of biotechnology for $R \& D$, innovation and production purposes (Rose and McNiven 2007).

First measurement experiences demonstrated that, unlike ICT or other technologies, biotechnology lacks a core 'sector' that can be quickly identified and surveyed. This has created major challenges for developing comparable biotechnology indicators. These include national differences in the definition of biotechnology and the fields of application of biotechnology, and of a biotechnology firm. To address these issues, over the past seven years the OECD has coordinated work by national experts to improve definitions and survey methodologies (OECD 2007: 227). The Ad Hoc Working Group met five times between 2000 and 2004. It established a statistical definition for biotechnology and proposed ways of applying the definition in R\&D surveys, dedicated biotechnology surveys and a patent classification. It also proposed a list of potential indicators, collection guidelines, classification schemes, and model questionnaires and surveys (OECD 2005b). 
According to the OECD recommendations, a single definition describes biotechnology as the application of S\&T to living organisms as well as parts, products and models thereof, to alter living or non-living materials for the production of knowledge, goods and services' (OECD 2009b: 9). This definition is supplemented by a so-called list-based definition, accepted by member countries in 2008 and including several biotechnology techniques in such sub-areas as DNA/RNA, proteins and other molecules, cell and tissue culture and engineering, process biotechnology techniques, gene and RNA vectors, bioinformatics and nanobiotechnology (OECD 2005b: 9). In addition to these definitions a number of criteria for identification of biotechnology-related firms, products and processes was elaborated. That allowed introducing a conceptual model and general measurement approach bringing together key biotechnology activities, techniques and elements of probable end uses of biotechnology products (mostly beyond the scope of the proposed approach) into existing statistical frameworks (OECD 2005b).

One possible classification approach is aimed at avoiding most of the diffculties experienced with current 'classifications' by considering three basic criteria that should be used to identify the main features of any 'technology' or 'technique':

(a) the field(s) of science on which its development has been based (scientific base or origin);

(b) the industries (goods and services) where it is actually applied (application);

(c) the socioeconomic dimensions most influenced by its diffusion and adoption (impact).

Following this proposal, some technologies will be classified only in terms of their scientific base (e.g. putatively 'emerging' technologies or techniques that have not yet found any specific application). In contrast, those technologies that are already diffusing into the economy could be more effectively classified also in terms of the industries where they are applied (e.g. extracting, manufacturing or service technologies) or in terms of expected societal impact ('energy-saving' or 'green' technologies). This approach should allow for providing the statistical framework with a robust classification base (as only official statistical classifications, and 


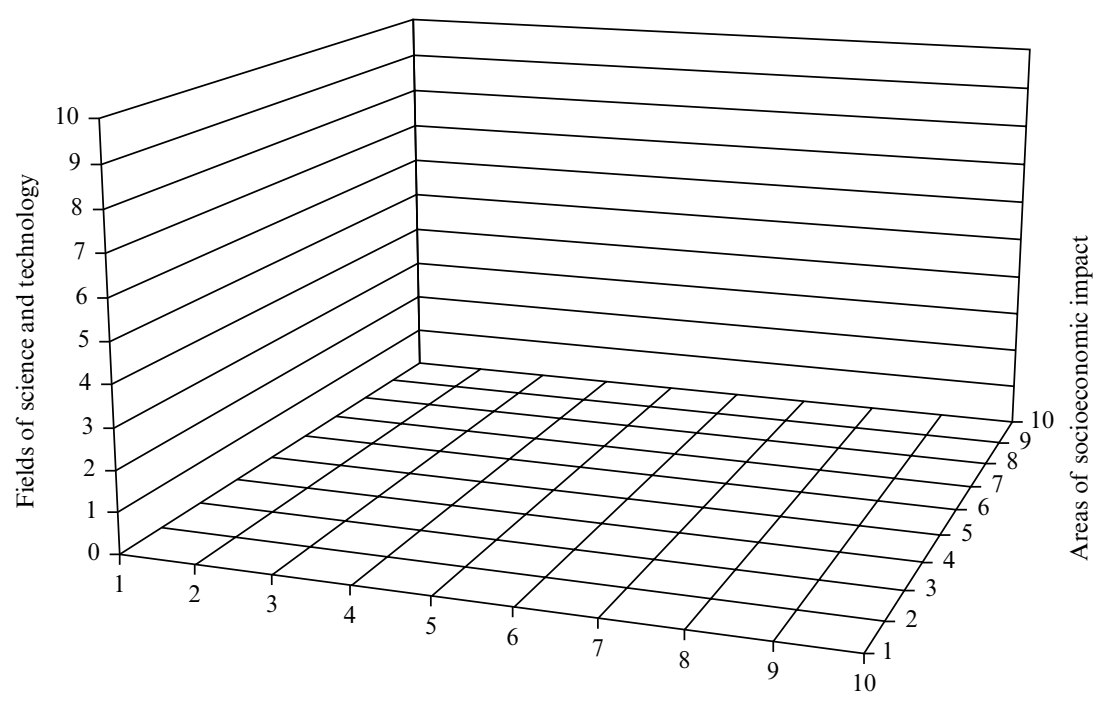

Fields of application (NACE/products)

Figure 15.2 A 3D visualization of an integrated system of classification for technologies

thus the data organized on their basis, will be used in this context, at least at the initial stage). It should also be able to deal with demand by users mainly by policy makers - for evidence on the results of their investments in S\&T.

By taking into account that the current classifications have, as a major shortcoming, the limitation of considering only a single aspect of technology development, it should be stressed that the proposed classification approach allows for a 'multidimensional' classification of technical knowledge that could be further developed in the future along two main lines of activity: improvement of the existing statistical classifications; and testing of a new multidimensional classification of technologies.

Figure 15.2 portrays the three dimensions that can contribute to a more inclusive classification system. The main conventional statistical classifications used currently in the international S\&T statistics domain are brought together: the Frascati FOS classification, the classification of economic activities adopted at the international level (either NACE or ISIC, which can be broken down by product groups by applying the related classifications used in the statistics on production), and the Frascati classification of Socio-Economic Objectives (SEO). Adoption of these classifications does not imply that these will be the ultimate categories in the new statistical framework: they could certainly be improved. For example, the FOS 
classification still relies on traditional boundaries among scientific fields, and provides few options to deal with multidisciplinarity. SEO classification shows that there is a general need to invest resources in evaluating and reorganizing classifications currently used in accordance with ongoing social and economic changes, and, moreover, to develop new ones - more suited to the new socioeconomic configurations that are emerging and, it is hoped, more helpful for the measurement of technology and technological activities that underpin this. At the same time, using existing classifications helps at least to reflect most recent technological advancements by levelling such multidisciplinary horizontal areas as ICT, bio- and nanotechnology within the conventional frameworks, similar to more traditional fields of science. In another case, new technologies are shaping new industries (for example one can see the rapid emergence of various web-related industries, from ISPs and server farms, to web design and mobile web services), and the current classification of economic activities may not always reflect these quite recent changes.

The sorts of data that could go into the cells of this 3D matrix should be described. For example, economic accounts would conventionally primarily deal with money (the value of inputs and outputs) or with people (the number of workers [or FTE workers] engaged here). But other data sets could be brought to bear, perhaps through satellite accounting or similar - for example the wave of studies of the diffusion of robotics across manufacturing, or PCs/Internet across the whole economy, yields data that could be fitted into such cells (e.g. the share of enterprises using ICT, per capita ICT investment).

Another possible path of development, missing from the current framework, is the occupational and educational levels (ISCO and ISCED) that demonstrate the need for new competencies for technology development/ processing. Going further still, one can see the accounting matrix extending into social accounting: the situation of the household economy, where some SEOs are instantiated, and where money and time are spent consuming (and often producing with the aid of) new technologies. Quite a few information society statistics examine this sort of thing - and social accounting matrices (SAMs) can be used to depict digital divides and the like.

Returning to the discussion of the identification and characterization of EETs, further development of such approaches should be a by-product of the actual statistical activity. The indicator system that will emerge from the new statistical framework will assist the elaboration of criteria to distinguish the moment when a specific technology starts to 'emerge', when it becomes relevant for measurement in terms of 'scientific productivity' and of technology creation, diffusion and use, which goods or services 
will be enabled (or affected otherwise) by relevant changes as a result of its application (potency), and which changes in the social and economic system will be caused by its diffusion. These are the criteria that - in connection with a common definition and general classification principles that can assist in describing the nature of new technology, uncovering one or more of its 'sub-components' and reflecting distinctive features of it - can help to identify the dynamic position of each single technology in the 3D matrix by highlighting its process of evolution from one position to another.

\section{RECOMMENDATIONS ON SURVEY STRATEGIES AND KEY INDICATORS}

Measuring EETs is a challenging task, dealing with growing potential innovations caused by results of technological development extending across various economic sectors. The existing rhetoric highlights the future success of technologies under development, while the de facto high level of the expectations is portrayed with the low range of indicators of technology-related activities. It should be noted that, in general, national statistical offices as well as research organizations have not actively participated in the elaboration of statistical data to provide evidence of EET development. These activities are locally addressed and commonly based on the integration of limited indicators (questions) into regular surveys. ${ }^{10}$ On the one hand, this allows to identify a population of organizations engaged in technological development and, on the other hand, to exploit the potential of existing measurement frameworks. Thus regular innovation surveys may be amended to include questions about the use of particular techniques or technologies; even the Labour Force Survey has been used as a vehicle to carry out enquiries about employee use of new ICTs, and categories reflecting new ICT consumer goods have been added into household expenditure surveys and so on.

Specialized regular surveys of more established technology domains, such as ICT or biotechnology, have been established in several countries. In some cases, topics that were at one time the focus of much attention have dropped somewhat from visibility, and so a wave of surveys of uptake of office automation and industrial robotics in the 1980s has largely subsided (although the 1990s and the first decade of the 2000s saw waves of new interest on topics such as Internet use and e-commerce). A few similar projects were started with the aim of an in-depth analysis of biotechnology. ${ }^{11}$ Some ad hoc surveys were addressed to distinct technology areas. ${ }^{12}$ Among the variety of projects related to the analysis of 
trends in nanotechnology development and using different qualitative and quantitative indicators, there are few examples of statistical observations as such. The forms and extent of data collection in the field of nanotechnology are also very diverse: from censuses of organizations (Israel, the USA and Canada) or individual researchers undertaking projects in nanotechnology (Mexico) to the study of public opinion (the USA, Japan, Russia and most EU countries) and assessment of personal experience of using nanotechnology-enabled products (Australia). In some cases, statistical questionnaires include indicators of innovative activity and industrial output (Russia), and some patent and bibliometric indicators (Belgium, France, Italy, Germany and Sweden). In most cases such studies are initiated by government agencies and carried out within the national nanotechnology initiatives or major programmes with the participation of manufacturing companies, non-profit organizations, universities and research centres.

Since a technology area (domain) is taken as an object for statistical observation, its identification and measurement require developing indicators, charaterizing economic inputs, outputs and impacts from their development and use. The EETs form a specific field in different areas of S\&T. Moreover, the cycle of EET development is integrated into the S\&T system, which lends itself well to a systemic analysis. One way in which the S\&T system can be presented involves the depiction of a system comprising education, research and innovation subsystems. They are introduced into an environment and receive input from this environment. The three subsystems use this input to create and produce technological outputs. If successful, new scientific knowledge and the EET that result from it are applied to create goods and services. The goods and services resulting from the new scientific knowledge and EET will be distributed, marketed, consumed and used. Finally the distribution, marketing, consumption and utilization activities of the new scientific knowledge and EET will have an impact on the environment. The sustainable development indicators will tell whether this impact is positive or not.

The EET indicator system can be superimposed on the overall S\&T system. The EET indicator system is divided into six major categories that form the main elements of the S\&T system: context, input, procedure, output, growth of knowledge and technological progress and, lastly, impact (Table 15.1). Activities that cross over from one category of indicators to another enable a global view of the development cycle of the EET. It is important to analyse and therefore to measure these activities. The indicators of incentive, utilization, creation and development, and then consumption, dissemination, and marketing of EETs also have to be developed. 
Table 15.1 Emerging and enabling technology indicator system

Contextual indicators

Economic, social, political and ecological environment, incentive structures

\begin{tabular}{|c|c|c|c|}
\hline Input indicators & $\begin{array}{l}\text { Process } \\
\text { indicators }\end{array}$ & Output indicators & Impact indicators \\
\hline $\begin{array}{l}\text { Sources } \\
\text { (financial, } \\
\text { personnel, } \\
\text { knowledge and } \\
\text { technological) } \\
\text { and public } \\
\text { funding }\end{array}$ & $\begin{array}{l}\text { Collaboration, } \\
\text { partnership, } \\
\text { HRST mobility } \\
\text { and skills, } \\
\text { technology } \\
\text { transfer }\end{array}$ & $\begin{array}{l}\text { Tacit knowledge } \\
\text { (graduates, diplomas } \\
\text { and certificates), } \\
\text { codified knowledge } \\
\text { and disembodied } \\
\text { technologies (scientific } \\
\text { publications, patents } \\
\text { and their citations, } \\
\text { licences, know-how } \\
\text { etc.), embodied } \\
\text { technologies } \\
\text { and innovations } \\
\text { (technological } \\
\text { advances, new and } \\
\text { advanced products and } \\
\text { processes) }\end{array}$ & $\begin{array}{l}\text { Direct impacts } \\
\text { (sales, employment, } \\
\text { market shares, final } \\
\text { user adoption etc.), } \\
\text { economic, social } \\
\text { and other indirect } \\
\text { impacts ( } \mathrm{CO}_{2} \\
\text { savings, energy } \\
\text { efficiency and } \\
\text { other sustainable } \\
\text { development } \\
\text { indicators and } \\
\text { responses to global } \\
\text { challenges) }\end{array}$ \\
\hline
\end{tabular}

Indicators on the cycle of development of EETs

IPR and technology commercialization, technology dissemination, utilization and consumption in industry, public sector and households

This indicators system can be applied to all EETs or to particular technological areas (ICT, biotechnology, nanotechnology, energy, environment, health etc.). This model recognizes existing and growing institutional structures and actors that generate, transmit and use S\&T knowledge by engaging in different activities. Given levels represent key stages of knowledge flows, taking into account their measurable forms and various inputs. At the same time outputs lead to a wide range of direct outcomes and indirect longer-term impacts connected in turn to key policy issues and global challenges. Since the model describes the flow of S\&T knowledge through the system, it also addresses environmental issues that provide a general context of EET development. In particular, output indicators can be partial measures of impacts while impacts can influence the social and economic objectives, creating incentive structures for generating new knowledge, and developing and disseminating new technologies, as the cycle begins again. 


\section{DEVELOPING A MONITORING SYSTEM FOR EETS - THE RUSSIAN EXPERIENCE WITH NANOTECHNOLOGY STATISTICS}

In most cases efforts to statistically measure technology at the national level have mainly been limited to three broad technological domains: ICT, biotechnology, and more recently nanotechnology, adopting existing OECD and Eurostat definitions and methodological guidelines. Although the nanotechnology case is not that widely spread, and lacks international harmonization, the Russian experience is particularly interesting, due to the high and clear demand for statistical evidence from decision makers (Gokhberg et al. 2011, 2012).

In Russia the beginning of an ambitious programme of nanotechnology development and, accordingly, statistical monitoring of this field, was laid by a presidential initiative ('The Development Strategy for Nanotechnology') adopted in 2007. It defined the need for a system of integrated information and analytical support to R\&D in nanotechnology to enable more efficient use of the financial and organizational resources in interdisciplinary research, with the aim of creating a competitive domestic supply of and market for nanotechnology-enabled products. On the other hand, practice of implementation of the existing R\&D initiatives and co-financing projects in the field of nanotechnology demonstrated different approaches to the understanding of activities related to nanotechnology. These emphasized the importance of organizing a unified system of statistical measurement based on common concepts and drawing on the experience of leading international organizations for standardization and statistics.

The work started with the elaboration of an operational definition of nanotechnology, which reflected its distinctive features and could be used in statistical surveys, as well as for policy making in S\&T and innovation. Current national practices of statistical studies of EETs as well as OECD recommendations on indicators and measurement of ICT and biotechnology (OECD 2009b, 2011) involve creating core and list-based definitions of the phenomenon under study to identify more clearly the subject of the survey, which in turn improves the quality of filling out statistical questionnaires and ensures the collection of complete and accurate information. This principle was taken to elaborate operational definition and classifications of nanotechnology.

A core definition for the Russian statistical system was developed as an umbrella concept to 'distinguish a set of methods and techniques for the analysis, design, and manufacture of nanostructures, devices, and systems, including targeted control and modification of the shape, size, interaction, 
and integration of the constituent elements of the nanoscale level, which brings improvements or additional performance and/or consumer properties to the resulting products' (Alfimov et al. 2010: 11). This definition took into account the integrated scientific and technological nature of the phenomenon of the targeted molecular manipulations and emphasized their decisive influence on the properties of the products created, and the market innovation status.

In the course of the work, a general definition of nanotechnology was completed featuring seven major areas of nanotechnology. They comprise the 'list-based definition' and form the basis for a local classification of nanotechnology areas. Besides, a grouping of the product types related to nanotechnology has been proposed, to be applied in the analysis of the degree of penetration by nanotechnology of the product. All together they formulated a kind of a 3D classification system to be used for statistical purposes. This represents a sophisticated move on from the ICT classification, and can be characterized as such.

The targeted goal of the classification system (Figure 15.3) determined a number of methodological principles to be taken into consideration. The 'principle of consistency and independence' of the three classifications integrated into a system suggests that together they cover the entire

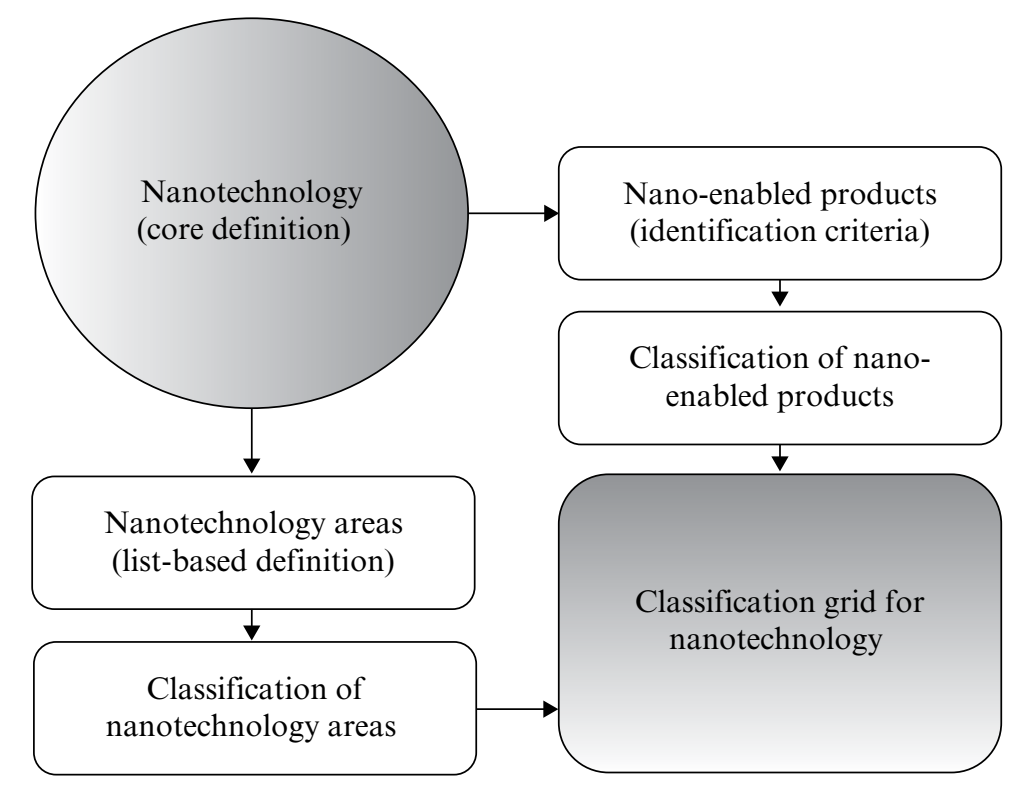

Figure 15.3 A classification grid for nanotechnology measurement in Russia 
innovation cycle, from $\mathrm{R} \& \mathrm{D}$ to manufacturing of products. This requires the formation of a consistent terminology and criteria for classification, reflecting the existing technology-product-market structures, and the integrity of the system vis-à-vis independence of specific classifications. This means a flexible system dealing with functionalities rather than the specific tools and techniques used at one point in time. The 'principle of harmonization and compatibility' answers the requirement for harmonization with basic international standards (ISO, ISIC/NACE etc.), correspondence to regular statistical practices for S\&T and innovation measurement, and compatibility with national standard classifications. The 'principle of openness and dynamism' implies the use for statistical and standardization purposes of diverse information and data sources, including statistical surveys, lists of actual and prospective research and technology areas, patent groups and nanotechnology-enabled products. The classification then allows to cover groups of already available nanotechnology-related goods and services as well as providing room for further expansion to emerging market niches. In addition to these principles the classification system required the development of a qualitative approach based on grouping products by types depending on the scale of the technology input that allowed taking an overview of nanotechnology as a research area and as a cross-industry activity.

\section{Developing Specialized Supporting Classifications}

In contrast to the core definition, the list-based definition is a more operational one, because it presents the object of observation in ways that are quantifiable for statistical purposes. To develop classification of nanotechnology areas the latter were considered primarily as a research field; and, indeed, much of the activity at this point is R\&D, even though commercial applications appear with increasing frequency. The first step was for a group of experts to identify seven nanotechnology areas on the basis of various national and international technical standards. Taking into account the multidisciplinary nature of nanotechnology, the following areas have been identified: ${ }^{13}$

A nanomaterials include as a research object a nanoscale ensemble of atoms or molecules with at least one dimension smaller than $100 \mathrm{~nm}$ and are structurally distinguishable from the surroundings;

B nanoelectronics brings together a group of technologies related to the study of physical principles of operation and development of architectures and manufacturing nanoscale electronic devices and functional devices based on them; 
C nanophotonics includes technologies related to the production of nanostructured devices for generation, amplification, modulation, transmission and detection of electromagnetic radiation, as well as the research methods aimed at understanding physical phenomena that determine the functioning of nanostructured devices and processes in the interaction of photons with nanoscale objects;

D nanobiotechnology is a research area related to the strategic use of biological macromolecules and organelles for the construction of nanomaterials and nanodevices;

E nanomedicine is regarded as a practical application of nanotechnology for the diagnosis, monitoring, targeted drug delivery, as well as of rehabilitation and reconstruction of biological systems of the human body, using nanostructures and nanodevices;

$\mathrm{F}$ methods and tools for the research and certification of nanomaterials and nanodevices include initial infrastructure for nanotechnology such as analytical, measuring and other equipment designed for manipulation of nanoscale objects as well as for control and standardization of the properties of nanomaterials and nanodevices;

$\mathrm{G}$ technologies and specialized equipment for experimental and industrial production of nanomaterials and nanodevices combine technological and engineering techniques associated with the development of processes and specialized equipment for the manufacturing of elementary nanoproducts.

The second step then involved the classification of groups of specific technologies highlighted by experts as related to the nanotechnology research area, classified according to the extracted technology areas. For each of the seven selected areas a number of positions, consisting on average of three to five technology sub-areas, has been proposed. For example, the area of nanomaterials included five sub-areas, characterizing its various types by the level of complexity and methods of design and experimental development.

Finally, a third step was the validation of this draft classification by representatives of a wider S\&T community to (1) assess the coverage of the proposed list of technology groups within the selected areas, (2) clarify proposed terminology and definitions, and (3) evaluate the consistency of the elaborated areas.

A specialized classification of nanotechnology-enabled products has been developed to measure manufacturing activities in nanotech-related industries.

It should be noted that both international and domestic practices of statistical surveying offer different interpretations of what is a 
nanotechnology-enabled product. A narrow interpretation suggests that only nanomaterials and nanodevices are treated as primary nanotechnology products. Following a wider approach, nanotechnology-related output includes conventional products that contain nanomaterials as integral components or that have been produced with the use of nano-enabled processes. The approach proposed for Russian statistics uses a block structure of the classification. Goods and services related to nanotechnology, depending on the latter's contribution to the composition of the final product, can be grouped for the statistical observation purposes into the following types:

I nanoproducts are the artificially created nanoscale components (nanoparticles, nanomaterials and nanosystems) that could be used for manufacturing other product categories with new or improved properties, functions and performance;

II conventional products containing nanocomponents are those integrating elementary nanoproducts in any proportion that determine their new or significantly improved functional and consumer properties;

III goods and services based on technological processes using nanotechnology involve the use of nanotechnology as a part of the overall process that contributes to a significant improvement in their performance, but contain no nanoproducts as an integral part;

IV tools and equipment for nanotechnology are a specific category bringing together the equipment required to perform various operations on the atomic and molecular levels in order to obtain, modify, produce, measure and control the properties of nanoproducts.

The block structure of the nanotechnology-enabled products classification allows adopting the abovementioned grouping principles for the further analysis of different nanotechnology markets as well as providing opportunities for complementing other statistical classifications and, thus, further comparisons with other types of statistical information (e.g. on $R \& D$ expenditure, production output etc.).

The methodological approach adopted in the early phases of establishing this area of statistics was largely aimed at upgrading existing surveys by incorporating new indicators for nanotechnology. The subsequent phases involve the design of various specialized surveys to cope with the fundamental novelty of this area for both national and international statistical practices. In this case, nanotechnology statistics in Russia were based on rigorous statistical methods rather than on ad hoc questionnaires, as happens in many countries. The earmarked classification 
of nanotechnology-related areas and nanotechnology-enabled products allowed extending the National Classification of Products by Types of Economic Activities (NCP) to be used in regular surveys.

The distribution of goods and services related to nanotechnology and manufactured in the entire economy, along the NCP classes, resulted in the identification of product groups notable for either similarities or differences according to certain selection criteria such as use of advanced nanomaterials and/or nano-enabled processes and their influence on the technical or consumer characteristics of the final product.

Such an approach provides Russian statistics with a multi-level classification, taking into account the cross-cutting nature of nanotechnologies. It makes it possible to relate nanotechnology to the structure of national economic activities. Furthermore, the grouping of goods and services in their relation to nanotechnology, depending on the specifics of allied manufacturing processes, supports the measurement of output, not only as total sales of nanotechnology-enabled products, but also by distinguishing their types and application categories for analytical purposes.

\section{ACKNOWLEDGEMENTS}

The authors would like to thank Fernando Galindo-Rueda (OECD) and Elisabeth Pastor (Swiss Federal Statistical Office) for their valuable contributions to the discussion and for providing materials.

\section{NOTES}

1. This chapter summarizes the key results of a study on developing a conceptual and methodological approach to statistical measurement of emerging, enabling and general-purpose technologies, carried out within the framework of the Basic Research Program of the National Research University Higher School of Economics (Moscow, Russia) in 2011-12.

2. According to the EU definition, key enabling technologies (KET) are knowledgeand capital-intensive technologies associated with research and development (R\&D) intensity, rapid and integrated innovation cycles, high capital expenditure and highly skilled employment. Their influence is pervasive, enabling process, product and service innovation throughout the economy. They are of systemic relevance, multidisciplinary and trans-sectorial, cutting across many technology areas with a trend towards convergence, technology integration and the potential to induce structural change. KETs can assist technological leaders in other fields to capitalize on their research efforts. These KETs are nanotechnology, micro- and nanoelectronics, advanced materials, photonics, biotechnology, along with advanced manufacturing technologies as a cross-cutting application (EC 2009).

3. The concept of technology convergence and the NBIC abbreviation seems to be first employed in Roco and Bainbridge (2002). However, further studies of S\&T develop- 
ment demonstrated that its various rhetorical uses are connected to earlier policy discourse around nano-convergence (Schummer 2010).

4. 'Early on I found out that words were a problem in technology ... Many of the ones used most heavily - "technology" itself, "innovation", "technique" - have overlapping and often contradicting meanings ... "Technology" has at least half-a-dozen major meanings, and several of these conflict' (Brian Arthur 2009: 5).

'In common parlance, nonetheless, when we refer to one of these complex systems as a technology, the material component more often than not serves as the tacit referent. But, that restricted sense of the word, as in the case of the railroad, can be ambiguous and misleading' (Marx 2010: 574).

5. Four main meanings are provided by the Merriam-Webster Dictionary:

(1) the practical application of knowledge especially in a particular area;

(2) a capability given by the practical application of knowledge;

(3) a manner of accomplishing a task especially using technical processes, methods, or knowledge;

(4) the specialized aspects of a particular field of endeavor.

6. 'A jet engine (or more generally, any technology) consists of component building blocks that are also technologies, and these consist of subparts that are also technologies, in a repeating (or recurring) pattern' (Brian Arthur 2009: 38-9).

7. 'In French, ... two separate concepts [are used]: "technique" is defined as a body of methodical processes based upon scientific knowledge that are used in production, and "technologie" as the study of techniques, tools, machines and materials' (OECD 1990: $10)$.

8. 'In German and other European languages, a distinction exists between "Technik" and "Technologie" that is absent in English, as both terms are usually translated as "technology"' (Schatzberg 2006: 487-8). In Russian, similarly, 'technics' usually means hardware equipment, while 'technology' is mostly applied to processes.

9. It should be noted, then, that codes for bio- and nanotechnology R\&D still do not allow relevant analyses since, for example, pharmaceuticals are listed as a separate category under the aggregate 'manufacture of chemicals and chemical products'.

10. From the perspective of a research analyst, a mirror strategy envisions collecting and matching secondary data from different sources. See, for example, Hullman (2006).

11. Canadian experience provides a good basis for further discussion on the topic and is documented in a series of working papers on the Canadian Biotechnology Use and Development Survey (Byrd 2002; McNiven 2001a, 2001b, 2002; McNiven et al. 2003; Traoré 2003).

12. Among one of the latest initiatives the Swiss Cleantech Report (Federal Department of Economic Affairs etc. 2011) should be mentioned.

13. For details of the definitions and approaches, see Alfimov et al. (2010).

\section{REFERENCES}

Alfimov, M., L. Gokhberg and K. Fursov (2010), 'Nanotechnology: definitions and classifications', Nanotechnologies in Russia, 5(7-8), 8-15 (in Russian).

Beniger, James R. (1986), The Control Revolution: Technological and Economic Origins of the Information Society, Cambridge, MA: Harvard University Press.

Brian Arthur, William (2009), The Nature of Technology, New York: Free Press.

Byrd, Craig (2002), 'Profile of Spin-off Firms in the Biotechnology Sector: Results from the Biotechnology Use and Development Survey - 1999', Statistics Canada Working Paper ST-02-04, http://www.statcan.ca/english/research/88F0006XIE/88F0006XIE2002004. pdf. 
Carey, J. and M.C.J. Elton (2009), 'The other path to the web: the forgotten role of videotex and other early online services', New Media \& Society, 11(1-2), 241-60.

Chen, Chaomei (2006), 'CiteSpace II: detecting and visualizing emerging trends and transient patterns in scientific literature', Journal of the American Society for Information Science and Technology, 57, 359-77.

Cobo, M.J., A.G. Lopez-Herrera, E. Herrera-Viedma and F. Herrera (2011), 'An approach for detecting, quantifying, and visualizing the evolution of a research field: a practical application to the fuzzy sets theory field', Journal for Informetrics, 5, 146-66.

Daim, T.U., G. Rueda, H. Martin and P. Gerdsri (2006), 'Forecasting emerging technologies: use of bibliometrics and patent analysis', Technological Forecasting and Social Change, 73, 981-1012.

EC (2009), Preparing for Our Future: Developing a Common Strategy for Key Enabling Technologies, Communication from the Commission to the European Parliament, the Council, the European Economic and Social Committee and the Committee of the Regions, Brussels: Commission of the European Communities.

The Federal Department of Economic Affairs and the Federal Department of the Environment, Transport, Energy and Communications (2011), Swiss Cleantech Report.

Freeman, Christopher and C. Perez (1988), 'Structural crises of adjustment: business cycles and investment behaviour', in Giovanni Dosi, C. Freeman, R. Nelson and L. Soete (eds), Technical Change and Economic Theory, London and New York: Pinter Publishing, pp. 38-66.

Gault, Fred (2010), Innovation Strategies for a Global Economy, Cheltenham, UK and Northampton, MA, USA: Edward Elgar Publishing.

Gault, Fred (2011), 'Social impacts of the development of science, technology and innovation indicators', UNU-MERIT Working Paper, 2011-008.

Gimel, F.L. (2003), 'Definitions. General features from the Oslo Manual Revision', in OECD/Eurostat Workshop on the Oslo Manual Revision, SDE-13/2003/LDG/amm, Paris: OECD.

Godin, Benoit (2005), Measurement and Statistics on Science and Technology: 1920 to the Present, London: Routledge.

Gokhberg, Leonid and Peter Bøegh-Nielsen (eds) (2007), Information Society Statistics in the Russian Federation: Harmonization with International Standards, Moscow: State University - Higher School of Economics.

Gokhberg, L., K. Fursov and O. Karasev (2012), 'Nanotechnology development and regulatory framework: the case of Russia', Technovation, 32(3-4), 161-2.

Gokhberg, L., I. Kuznetsova, K. Fursov and V. Dalin (2011), 'Statistics of nanotechnology in Russia: formation of a new area', Issues of Statistics, 9, 3-20 (in Russian).

Griliches, Zvi H. (1987), R\&D, Patents, and Productivity, Chicago, IL: The University of Chicago Press.

Guo, H., S. Weingart and K. Borner (2011), 'Mixed-indicators model for identifying emerging research areas', Scientometrics, 89(1), 421-35.

Helpman, E. and M. Trajtenberg (1994), 'A time to sow and a time to reap: growth based on general purpose technologies', NBER Working Paper 4854, Cambridge, MA: National Bureau of Economic Research.

Hullman, Angela (2006), The Economic Development of Nanotechnology: An Indicators Based Analysis, Brussels: European Commission, DG Research.

Landes, David (2003), The Unbound Prometheus: Technical Change and Industrial Development in Western Europe from 1750 to the Present, New York: Cambridge University Press.

Lipsey, R.G., C. Bekar and K. Carlaw (1998), 'What requires explanation?', in Elhanan Helpman (ed.), General Purpose Technologies and Economic Growth, Cambridge: MIT Press, pp. 14-54.

Machlup, Fritz (1962), The Production and Distribution of Knowledge in the United States, Princeton, NJ: Princeton University Press. 
Mansfield, Edwin (1983), 'Long waves and technological innovation', The American Economic Review, 73(2), 141-5.

Marx, Leo (2010), 'Technology: the emergence of a hazardous concept', Technology and Culture, 51(3), 561-77.

McNiven, Chuck (2001a), 'Biotechnology use and development, 1999', Statistics Canada Working Paper ST-01-07, http://www.statcan.ca/english/research/88F0006XIE/88F0006 XIB2001007.pdf.

McNiven, Chuck (2001b), 'Practices and activities of Canadian biotechnology firms: results from the Biotechnology Use and Development Survey - 1999', Statistics Canada Working Paper ST-01-11, http://www.statcan.ca/english/research/88F0006XIE/88F0006 XIB2001011.pdf.

McNiven, Chuck (2002), 'Use of biotechnologies in the Canadian industrial sector: results from the Biotechnology Use and Development Survey - 1999', Statistics Canada Working Paper ST-02-03, http://www.statcan.ca/english/research/88F0006XIE/88F0006 XIE2002003.pdf.

McNiven, C., L. Raoub and N. Traoré (2003), 'Features of Canadian biotech innovative firms: results from the Biotechnology Use and Development Survey - 2001', Statistics Canada Working Paper ST-03-05, http://www.statcan.ca/english/research/88F0006XIE/8 8F0006XIE2003005.pdf.

Miles, Ian (1991), 'Measuring the future: statistics and the information age', Futures, 23, 915-34.

Morel, C.M., S.J. Serruya, G.O. Penna and R. Guimaraes (2009), 'Co-authorship network analysis: a powerful tool for strategic planning of research, development and capacity building programs on neglected diseases', PLOS Neglected Tropical Diseases, 3(8), 1-7.

OECD (1990), OECD Proposed Standard Method of Compiling and Interpreting the Technology Balance of Payments Data, Paris: OECD.

OECD (1992), OECD Proposed Guidelines for Collecting and Interpreting the Technological Innovation Data - Oslo Manual, OCDE/GD (92)26, Paris: OECD.

OECD (2001), Measuring Productivity: Measurement of Aggregate and Industry-Level Productivity Growth, Paris: OECD.

OECD (2002), Frascati Manual: Proposed Standard Practice for Surveys on Research and Experimental Development, Paris: OECD.

OECD (2005a), Handbook on Economic Globalisation Indicators, Paris: OECD.

OECD (2005b), A Framework for Biotechnology Statistics, Paris: OECD.

OECD (2007), OECD Science, Technology and Industry Scoreboard 2007, Paris: OECD.

OECD (2008), OECD Glossary of Statistical Terms, Paris: OECD.

OECD (2009a), OECD Patent Statistics Manual, Paris: OECD.

OECD (2009b), Biotechnology Statistics, Paris: OECD.

OECD (2010), Measuring Innovation: A New Perspective, Paris: OECD.

OECD (2011), Guide to Measuring the Information Society, Paris: OECD.

OECD/Eurostat (1997), OECD Proposed Guidelines for Collecting and Interpreting Technological Innovation Data - Oslo Manual, Paris: OECD.

OECD/Eurostat (2005), Oslo Manual: Guidelines for Collecting and Interpreting Innovation Data, 3rd edn, Paris: OECD

Porat, Mark U. (1977), 'The information economy: definition and measurement', US Department of Commerce, Office of Telecommunications, OT Special Publication 7712(1), Washington, DC: US Government Printing Office.

Roco, M.C. and W.S. Bainbridge (eds) (2002), Converging Technologies for Improving Human Performance: Nanotechnology, Biotechnology, Information Technology and Cognitive Science, Washington, DC: NSF/DOC.

Rose, Antoine (1997), 'Biotechnology research and development (R\&D) in Canadian industry: a portrait of large performers in 1997', Science Statistics, 24(2), Ottawa: Statistics Canada.

Rose, Antoine and Chuck McNiven (2007), 'Biotechnology: from measures of activities, linkages and outcomes to impact indicators', in OECD, Science, Technology and Innovation Indicators in a Changing World: Responding to Policy Needs, Paris: OECD, pp.215-30. 
Schatzberg, Eric (2006), 'Technik comes to America: changing meanings of technology before 1930', Technology and Culture, 47(3), 486-512.

Schummer, Joachim (2010), 'From nano-convergence to NBIC-convergence: "The best way to predict the future is to create it"', in Mario Kaiser, Monica Kurath, Sabine Maasen and Christoph Rehmann-Sutter (eds), Governing Future Technologies: Nanotechnology and the Rise of Assessment Regime, Sociology of the Sciences Yearbook 27, London and New York: Springer.

Shibata, N., Y. Kajikawa, Y. Takeda and K. Matsushima (2008), 'Detecting emerging fronts based on topological measures in citation networks of scientific publications', Technovation, 28, 758-75.

Smil, Vaclav (2005), Creating the Twentieth Century: Technical Innovations of 1867-1914 and Their Lasting Impact, Oxford and New York: Oxford University Press.

Traoré, Namatié (2003), 'Bioproducts development by Canadian biotechnology firms: findings from the 2001 Biotechnology Use and Development Survey', Statistics Canada Working Paper ST-03-13, http://www.statcan.ca/english/research/88F0006XIE/88F0006 XIE2003005.pdf.

Upham, Phineas S. and Henry Small (2010), 'Emerging research fronts in science and technology: patterns of new knowledge development', Scientometrics, 83, 15-38.

Van Merkerk, Rutger O. and Ruud E.H.M. Smits (2008), 'Tailoring CTA for emerging technologies', Technological Forecasting and Social Change, 75, 312-33.

Van Merkerk, Rutger O. and Harro van Lente (2005), 'Tracing emerging irreversibilities in emerging technologies: the case of nanotubes', Technological Forecasting and Social Change, 72(9), 1094-111.

Van Raan, Anthony F.J. (1996), 'Advanced bibliometric methods as quantitative core of peer review based evaluation and foresight exercises', Scientometrics, 36(3), 397-420.

Veugelers, Reinhilde (2007), 'Developments in EU statistics on science, technology and innovation: taking stock and moving closer to evidence-based policy analysis', in OECD, Science, Technology and Innovation Indicators in a Changing World: Responding to Policy Needs, Paris: OECD, pp. 33-47.

Youtie, J., M. Iacopetta and S. Graham (2008), 'Assessing the nature of nanotechnology: can we uncover an emerging general purpose technology?', Journal of Technology Transfer, 33, 315-29. 